\title{
Differential Expression of Cerebellar Metabotropic Glutamate Receptors mGLUR2/3 and mGLUR4a after the Administration of a Convulsant Drug and the Adenosine Analogue Cyclopentyladenosine
}

\author{
Elena Silvia Girardi · Juan Canitrot · Marta Antonelli · \\ Nélida N. González · Héctor Coirini
}

Accepted: 28 December 2006/ Published online: 31 March 2007 (C) Springer Science+Business Media, LLC 2007 ment decreased this immunostaining. Repetitive administration of MP and CPA induces an increased cerebellar mGluR2/3 and a decreased mGluR4a immunostaining, suggesting a distinct participation of both receptors that may be related to the type of cell involved. A protective action and /or an apoptotic effect may not be discarded. CPA repetitive administration although increase seizure latency, cannot prevent seizure activity.

Keywords Metabotropic receptors - mGluR2/3 . mGluR4a $\cdot$ Cerebellum · Epilepsy $\cdot$ Adenosine . Seizure $\cdot$ Convulsant drug · Cyclopentyladenosine . 3-Mercaptopropionic acid

\section{Introduction}

Glutamate, the major excitatory neurotransmitter in the central nervous system (CNS), plays a crucial role in seizure generation and maintenance as well as in excitotoxic epileptic brain damage [1, 2]. Glutamate acts through two principal classes of receptors, ionotropic and metabotropic (mGLuR) receptors. The latter have been involved in synaptic transmission, synaptic modulation and plasticity. These receptors present seven transmembrane domains that modulate intracellular second messengers via GTP-binding proteins [3, 4]. It has been described at least eight types of mGluRs that have been subdivided into three main groups based on sequence homology, signal transduction mechanism and response to receptor agonists. Group I (mGluR1; mGluR5) is linked to stimulation through inositol triphosphate (IP3) formation. Group II (mGluR2; mGluR3) and group III (mGluR4,

\author{
H. Coirini \\ Department of Human Biochemistry, IBYME-CONICET, \\ Facultad de Medicina. UBA, Buenos Aires, Argentina \\ Instituto de Biología Celular y Neurociencia "Prof. Eduardo \\ De Robertis" Facultad de Medicina, Universidad de Buenos \\ Investigaciones Científicas y Técnicas (CONICET), \\ Paraguay \\ e-mail: egirardi@mail.retina \\ M. Antonelli \\ IQUIFIB, UBA-CONICET, Buenos Aires, Argentina
}


mGluR6, mGluR7 and mGluR8) are coupled to adenylcyclase inhibition $[3,5]$. The cellular distribution of the metabotropic receptors in the rat brain has been achieved by immunohistochemitry and electron microscopy studies in the rat brain, exhibiting a complex regional pattern of differential localization [6-9]. Although members of each of the mGluRs groups can be located at both pre and postsynaptically, group II and III typically act as presynaptic receptors involved in neurotransmitters release regulation $[10,11]$.

Adenosine, considered an endogenous anticonvulsant, inhibits neuronal firing, synaptic transmission and modifies cyclic AMP levels [12, 13].These effects are due principally to the activation of the inhibitory A1 receptors, the most abundant of the four kind of adenosine receptors described $[12,13]$. In relation to this protective effect, we have found that the administration of cyclopentyladenosine (CPA), an adenosine analogue, and the convulsant 3-mercaptopropionic acid (MP) increase $\left[{ }^{3} \mathrm{H}\right]$-2-chloro-N6-cyclopentyl-adenosine (CCPA) binding to A1 receptors in different regions of the central nervous system [14]. In addition the administration of one unique dose of CPA before the convulsant MP produces a delay in seizure appearance [15], and it has been associated to changes on the specific $\left[{ }^{3} \mathrm{H}\right]-\mathrm{MK}-801$ binding. It was observed a decrease in this ligand binding to NMDA receptor in different brain areas after MP and CPA treatment [16].

The cerebellar cortex has a well characterized ultrastructure and cellular organization. [17, 18]. This brain area is rich in adenosine A1 receptors and expresses the different groups of mGluR $[8,14]$. The cerebellum is involved in the control of movements, particularly those where timing is crucial or is linked to the voluntary actions. Changes in excitatory synaptic strength in the cerebellar cortex have been associated to motor learning [19]. In addition it is an essential node in the central integration of somatic and visceral activities adapting the changes of internal and external environments [20]. Cerebellar stimulation is known to have inhibitory effects on seizures $[21,22]$ but cerebellar dysplastic lesions can be epileptogenic. In this regard it has been reported that a hemorrhagic cerebellar lesion produced epilepsia partialis continua in a patient [23].

The aim of this study was to evaluate cerebellar mGluR2/3 and mGluR4a alterations in an MP-induced seizure model and assess the role of the adenosine analogue as a neuromodulator, using immunocytochemical techniques.

\section{Experimental procedures}

Animals and treatments

Male Wistar rats (250-300 g) were maintained on a $12 / 12 \mathrm{~h}$ diurnal cycle. They were divided in four experimental groups ( $n=4$ /group). Rats were daily injected intra peritoneal (ip) during 4 days with a single dose of: a) $45 \mathrm{mg}$ of 3-mercaptopropionic acid/ $\mathrm{kg}$ body weight (MP group), b) $2 \mathrm{mg}$ of cyclopentyladenosine $/ \mathrm{kg}$ body weigh (CPA group) or c) the same dose of CPA $30 \mathrm{~min}$ before MP injection (CPA+MP group), control animals (CTL) were injected with saline as vehicle. Animal care was in accordance with the National Institutes of Health guideless for the care and use of laboratory animals and the principles presented in the guidelines for the use of animals in neuroscience research by the Society for Neuroscience. Daily MP injection (freshly prepared $\mathrm{pH}$ neutral MP solution) resulted in the onset of seizures episodes which occurred 5-8 min after MP injection, characterized by excitation with sudden running fits and convulsions which lasted 3-5 min. Rats injected i.p. with CPA (freshly dissolved in saline) resulted in a relaxed and inactive state at $30 \mathrm{~min}$. The third group of rats injected with CPA 30 min before MP showed an increase in MP seizure latency. Control group was injected with saline for 4 days.

Immunohistochemistry Twenty four hours after the last injection, animals were deeply anaesthetized with $300 \mathrm{mg} / \mathrm{kg}$ of chloral hydrate and perfused through the left ventricle, initially with a cold solution containing $0.05 \% \mathrm{w} / \mathrm{v} \mathrm{NaNO}_{2}$ plus $50 \mathrm{IU}$ of heparin in $0.1 \mathrm{M}$ phosphate buffer ( $\mathrm{pH}$ 7.4) followed by a fixative solution (4\% paraformaldehyde plus $0.25 \%$ glutaraldehyde in $0.1 \mathrm{M}$ phosphate buffer, $\mathrm{pH}$ 7.4). Each cerebellum was removed and kept in the same cold fixative solution for $4 \mathrm{~h}$. After that, tissue was washed three times in cold $0.1 \mathrm{M}$ phosphate buffer $\mathrm{pH} 7.4$ containing $5 \% \mathrm{w} / \mathrm{v}$ sucrose, and left in this washing solution for $18 \mathrm{~h}$ at $4^{\circ} \mathrm{C}$. Saggital $40 \mu \mathrm{m}$ thick sections were cut using an Oxford vibratome. Sections were cryoprotected with $25 \%$ sucrose in $0.1 \mathrm{M}$ phosphate buffer $\mathrm{pH} 7.4$ and stored at $-20^{\circ} \mathrm{C}$. Free floating tissue sections of all groups were simultaneously processed for immunostaining. Endogenous peroxidase activity, was inhibited on tissue sections using $0.5 \% \mathrm{v} / \mathrm{v}_{2} \mathrm{O}_{2}$ in methanol for $30 \mathrm{~min}$ at room temperature (RT). Tissue sections were blocked for $1 \mathrm{~h}$ with $3 \% \mathrm{v} / \mathrm{v}$ normal goat serum in phosphate buffer saline (PBS) and then incubated for $48 \mathrm{~h}$ at $4{ }^{\circ} \mathrm{C}$ with rabbit anti-mGluR2/3 (1:400) or anti-mGluR4 (1:800) primary antibodies. 
After five rinses in PBS, sections were incubated for $1 \mathrm{~h}$ at RT with biotinylated secondary antibody (1:100). After further washing in PBS, sections were incubated for $1 \mathrm{~h}$ with streptavidin-peroxidase complex diluted 1:200. Section were washed 5 times in PBS and 2 times in $0.1 \mathrm{M}$ acetate buffer $\mathrm{pH} 6$ (AcB), development of peroxidase activity was performed with $0.035 \% \mathrm{w} / \mathrm{v} 3,3$ '-diaminobenzidine plus $2.5 \% \mathrm{w} / \mathrm{v}$ nickel ammonium sulphate and $0.1 \% \quad \mathrm{v} / \mathrm{v} \quad \mathrm{H}_{2} \mathrm{O}_{2}$ in AcB. Sections were then washed in AcB 3 times and once in distilled water. Sections were mounted on gelatin-coated slides, dehydrated and cover-slipped using Permount (Sigma) for light microscopic observation. All antibodies, as well as streptavidin complex, were dissolved in PBS containing 1\% v/v normal goat serum and $0.3 \% \mathrm{v} / \mathrm{v}$ Triton X-100 (pH 7.4). PBS buffer used in washing steps included $0.025 \%$ Triton X-100. Negative controls were processed simultaneously by omiting the primary antibodies. Four to six assays for each primary antibody using 6-10 tissue sections for animal/group were made.

Image analysis

Optical density (OD) and morphometric parameters of immunostained cells were measured using an Axiophot Zeiss light microscope, equipped with a video camera on line with a Zeiss-Kontron Vidas image analyzer. Images obtained from the light microscope were transferred to an interactive image analysis system on line using a video camera. The images were digitized into an array of $512 \times 512$ pixels corresponding to $140 \times 140 \mu \mathrm{m}(40 \times$ primary magnification $)$. The resolution of each pixel was 256 gray levels ( 8 bits). After automatic normalization of gray scale, an interactive delineation and contrast enhancement of the cell images were performed, following the removal of interfering nonspecific images. The projected surface of cells was measured using mean grey values. Relative optical density (ROD) was obtained after a transformation of mean grey values into ROD by using the formula ROD: log (256/mean grey). A background parameter was obtained from each section out of the labeled structures and subtracted to each cell ROD before statistically processing values. Seven to ten fields were digitalized for each stained section. All cells from every field were measured.

\section{Statistics}

Values represent the means of 3-4 independent experiments. Inter-animal differences inside the groups were not significant. Individual experiments were composed of 6-10 tissue sections of each animal from each group. Seven to ten fields were measured for each cerebellum. Differences among the means were analyzed using one-way ANOVA and Student-NewmanKeuls post test. Statistical significance was set to $P<0.05$.

\section{Materials}

MP, CPA, streptavidin complex, secondary antibodies were obtained from Sigma-Aldrich. Polyclonal rabbit antiserum against mGluR2/3 and mGluR4a were purchased from Upstate Biotechnology. All other chemical substance were of analytical grade.

\section{Results}

Immunocitochemical analysis of the expression of mGluR2/3 and mGluR4a in cerebellar cortex showed differential localization and concentration (Fig. 1).

mGluR2/3 immunostaining was intense on the granular layer closely apposed to the Purkinje cell layer (Fig. 2A). Treatments with MP, CPA and $\mathrm{CPA}+\mathrm{MP}$ increased mGluR2/3 immunoreactivity (Fig. 2). Densitometric analysis showed that mGluR2/ 3 staining intensity was significantly increased in both independent drug treatments: MP (61\%), and CPA (53\%). When CPA was administered $30 \mathrm{~min}$ before MP the staining intensity showed a greater increase $(85 \%)$ that was not statistically significant among treatments (Fig. 3).

On the other hand, mGluR4a reactivity was mainly observed around Purkinje cells. The immunoreactivity in the molecular layer appeared as a shadow, avoiding a precise quantitative analysis (Fig. 4). Treatment with MP, CPA and CPA+MP decreased the immunostaining. Densitometric analysis showed that mGluR4a staining intensity was significantly decreased after MP (35\%) and CPA (54\%) treatment when compared to control. However when CPA was administered before MP the staining intensity was lower than the observed for each individual treatment (89\%) (Fig. 5).

CPA administration previous MP during four days, shows a delay on the onset of seizure (Fig. 6).

\section{Discussion}

In the present study, the effect of MP-induce seizures and adenosine analogue CPA on group II and III mGluR expression was evaluated on rat cerebellum. 
Fig. 1 Photograph of mGluR immunostaining in cerebellum. (A) mGluR 4a. The three layers are named. Molecular, Purkinje and Granular layers. Arrow shows Purkinje cells. (B) mGluR2/3 molecular and Purkinje cell layers are not stained (arrow). Original magnification $100 \times$
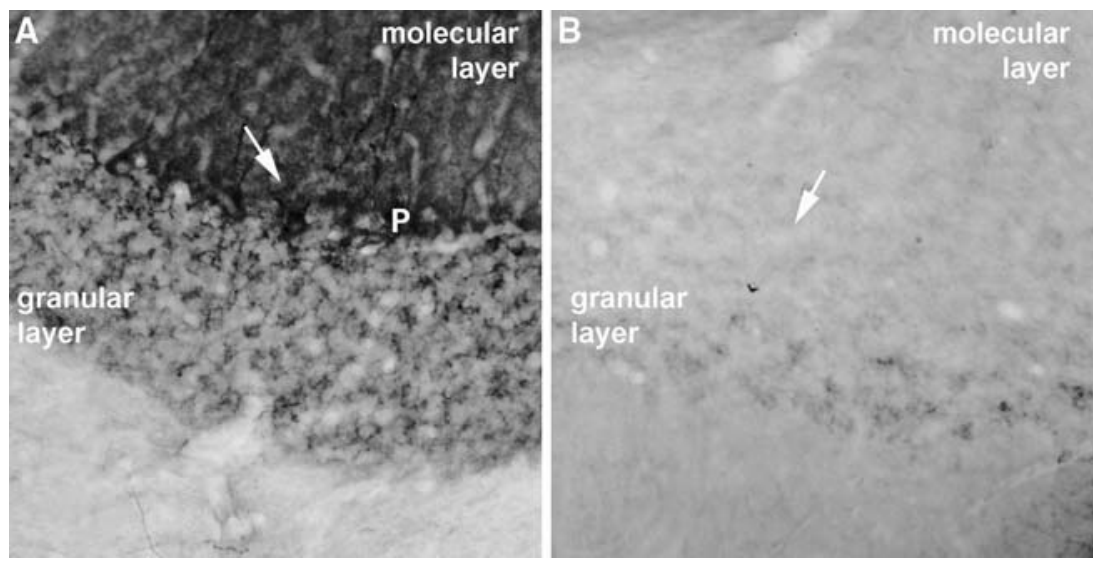

Fig. 2 Photograph of mGluR 2/3 immunostaining. (A) Control, (B) CPA, (C) MP, (D) $\mathrm{CPA}+\mathrm{MP}$. Original magnification $400 \times$. Note the increased immunostaining in $\mathrm{CPA}+\mathrm{MP}(\mathrm{D})$
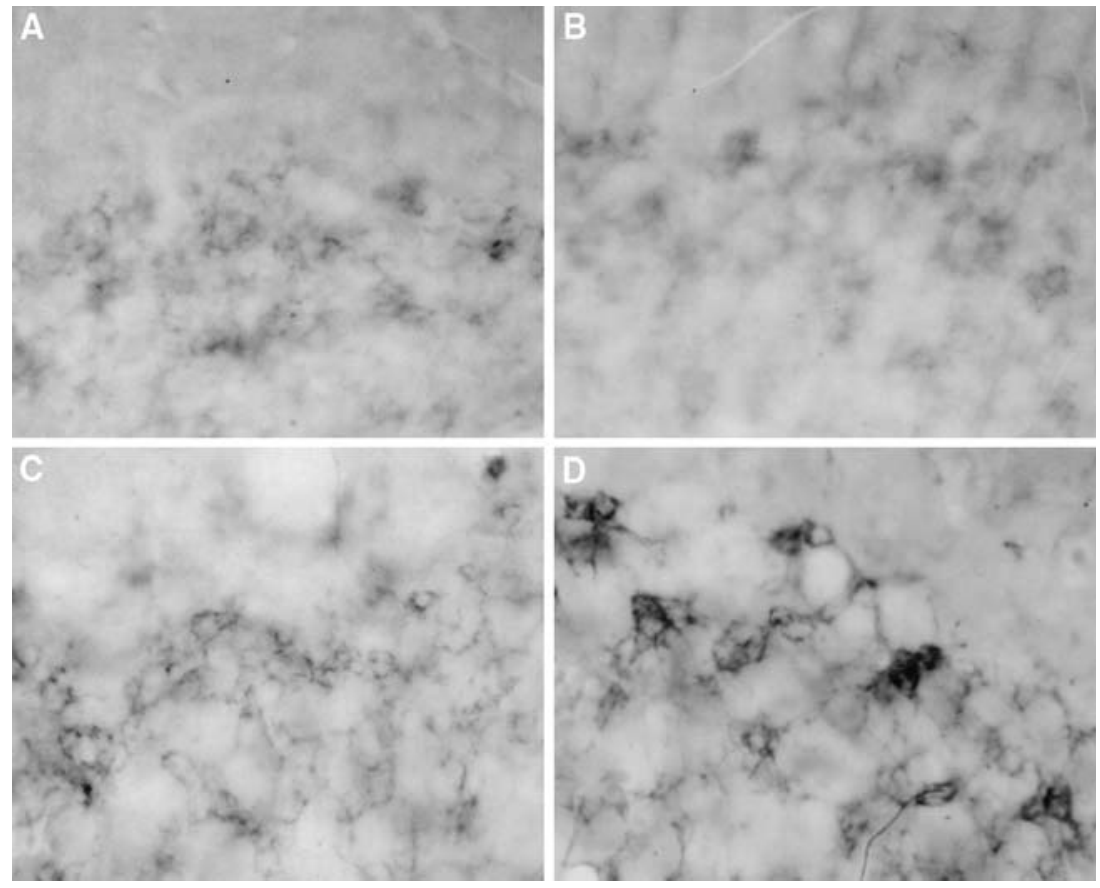

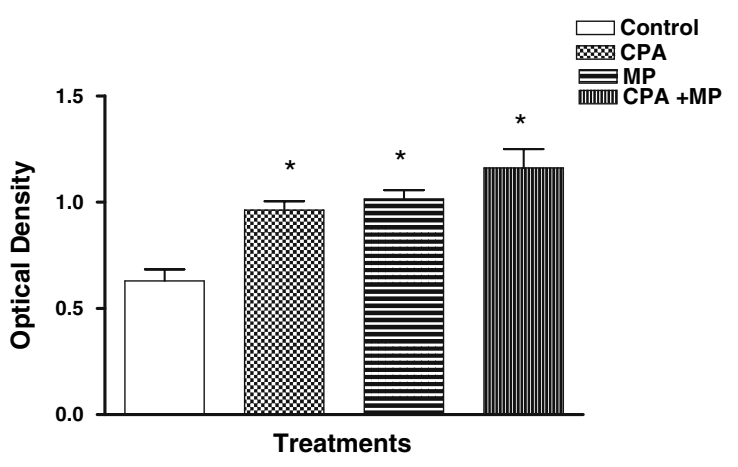

Fig. 3 Relative optical density of mGluR2/3 immunostained granular cells after control, CPA, MP and CPA+MP treatments. Values are expressed as the mean \pm SEM. Data were analyzed by one way ANOVA followed by Student-Neumann-Keuls test. $* P<0.05$ related to control. No statistically difference was observed among different treatments
In a previous work we demonstrated that MP administration induced an increase in $\left[{ }^{3} \mathrm{H}\right]-\mathrm{CCPA}$ binding to adenosine receptor in cerebellum slices [14] as well as an increase in 5'nucleotidase activity, the key enzyme in adenosine production during seizure, in cerebellar subcelullar fractions [24]. In addition, stimulation of this enzyme by neurotoxic concentrations of glutamate on culture granulare cells has been reported [25].

The role of the cerebellum in epilepsy is controversial, some reports indicate inhibitory effects on seizures after cerebellar stimulation [21, 22] and there are reports of Epilepsia partialis continua possibly caused by cerebellar lesion [23] and an epilepsy syndrome of infant with seizures of cerebellar origin [26]. Moreover Purkinje cell loss/injury was observed in the cerebellum of epileptic patients [27]. 
Fig. 4 Photograph of mGluR 4a immunostaining. (A) Control, (B) CPA, (C) MP, (D) $\mathrm{CPA}+\mathrm{MP}$. Original magnification $400 \times$. Note the reduced immunostaining in treatments respect to control
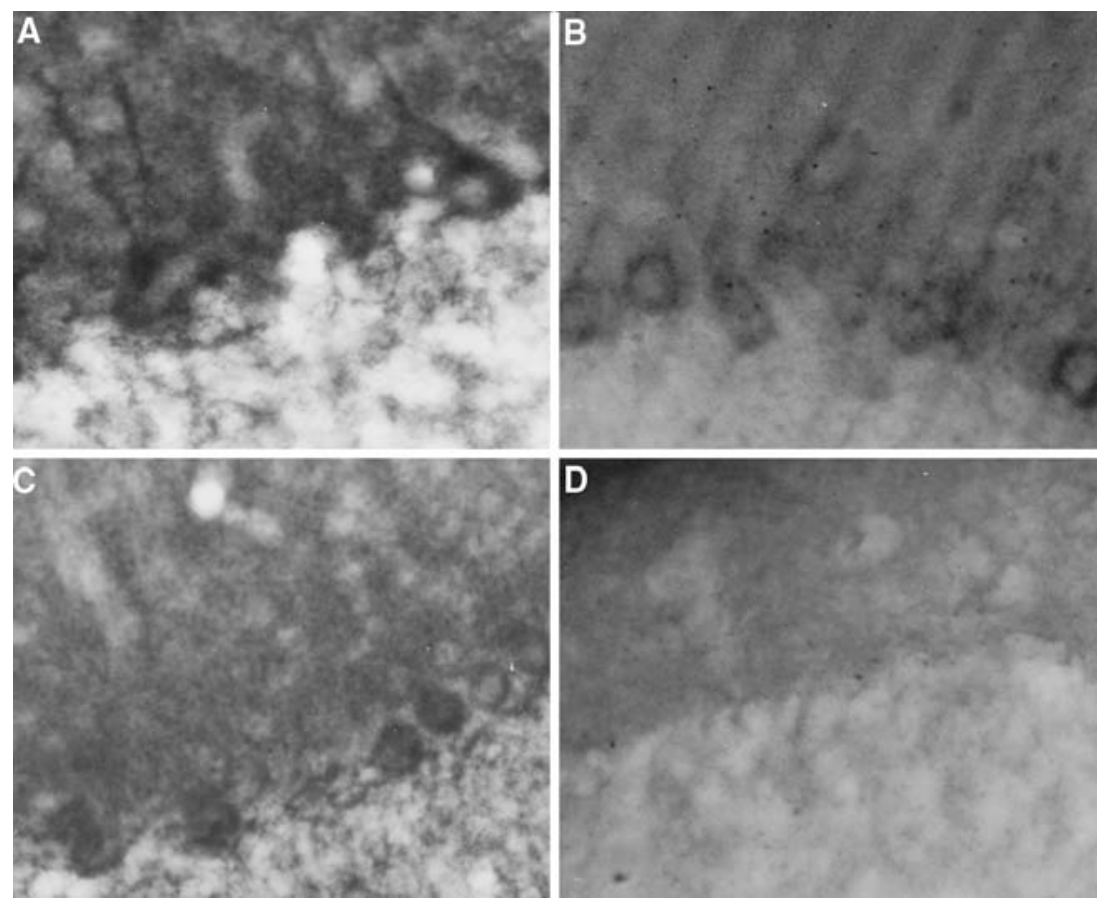

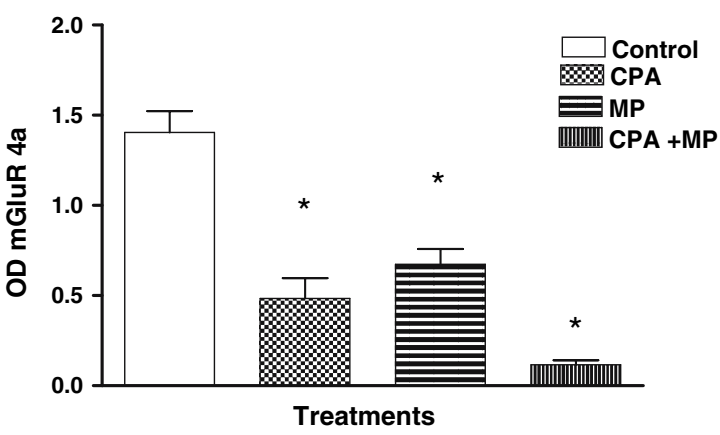

Fig. 5 Relative optical density of mGluR4a immunostained Purkinje cells after control, CPA, MP and CPA+MP treatment. Values are expressed as the mean \pm SEM. Data was analyzed by one way ANOVA followed by Student-Neumann-Keuls test. $* P<0.001$ related to control. Statistically difference was observed among different treatments $(P<0.01)$ except CPA versus MP

The cerebellar cortical structure consists in three layers: the molecular, the Purkinje cell and the granular cell layers. We observed that mGluR2/3 is preferentially expressed in the granular layer. Our results are in agreement with those reported by other authors $[9,28]$ that described mGluR $2 / 3$ expression in the cell body of the granular layer, dendrites and axon terminals of Golgi cells. Daily and repetitive MPinduced seizures increased mGluR2/3 expression, in granular layer. In addition CPA treatment alone and CPA injected before MP tends to enhance the MP alone treatment effect. In this regard activation of the

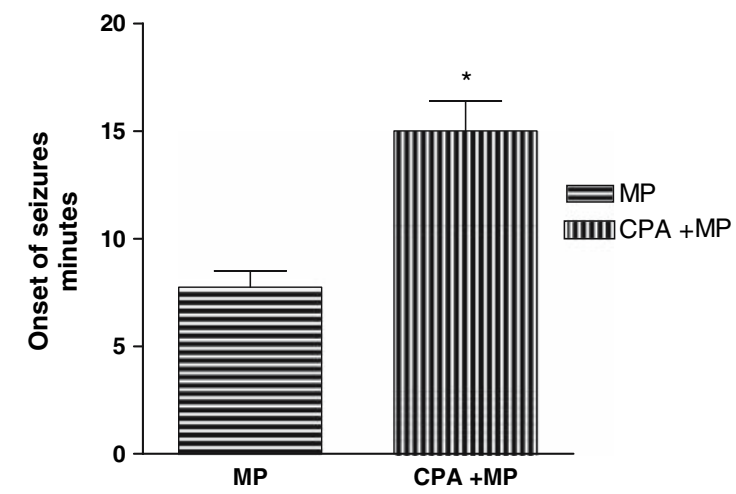

Fig. 6 Effect of CPA $(2 \mathrm{mg} / \mathrm{kg})$ administration $30 \mathrm{~min}$ previous to MP (45 mg/kg) during 4 days, CPA delays seizure appearance. Statistically difference $P<0.001$

mGluR2/3 receptors provides a negative feedback mechanism to prevent excessive presynaptic glutamate release in brain regions that have been implicated in pathologic disorders and it was reported that mGluR2/ 3 agonists prevent or inhibit different induced seizure models through activation of its presynaptic group II mGluRs receptors. In addition DBA/2 mice were protected against audiogenic seizures with (S)-4carboxy-3-hydroxyphenyl glycine, an antagonist of mGluR1a that also acts as an agonist of mGluR2 [29].

In the model of seizures induced in immature rats by bilateral intracerebroventricular infusion of DL-homocysteic acid, the group II mGluR agonist (2R, 4R)-4aminopyrrolidine-2,4-dicarboxylate (2R,4R-APDC) 
has an anticonvulsant and potent neuroprotective effect against seizures [30]. The authors concluded that seizures induced in their model indicate a complex role of mGluR in epilepsy suggesting that the response will depend not only of the levels of mGluR subtype modified but also of the concentration of agonists and/ or antagonists employed and perhaps the seizure model used [31]. According with this Tang et al. [32] were unable to find a protective effect using different intravenous injection doses of 2R,4R-APDC in a model of pilocarpine-induced status epilepticus in adult rats. On the other hand the selective group II mGluR agonist (+)-2-aminobicyclo-[3.1.0]hexane-2,6dicarboxylic acid (LY 354740) administered prior to the injection of pentetrazole or picrotoxin produced a dose-dependent decrease in the number of mice exhibiting clonic convulsions [33]. Moreover it is interesting to mention that the group II receptor agonist failed to suppress the hypersusceptibility to pentylenetetrazol- induced seizure in diazepam-withdrawn mice, but significantly increased the threshold for pentylenetetrazol-induced seizure in control mice [34].

As far as the agonists for group III mGluRs are concerned, the application of classical agonists L-AP4 (L-2-amino-4-phosphonobutyric acid) or L-SOP (L-serine- $O$-phosphate) attenuated the seizures induced by 3,5-DHPG ((R,S)-3,5-dihydroxyphenylglycine) [35].

Adenosine, a protective neuromodulator, is involved along with the mGluRII receptors in presynaptic inhibition. The increase in mGluR $2 / 3$ immunostained cells after CPA administration could be associated to this inhibitory effect. Our experiments show an increase in mGluR2/3 immunostaining that was enhanced when CPA has been administered previously to MP. Although this difference was not statistically significant, it could be indicating a probable protective effect.

In agreement, Glitsch et al. [36] suggested that depolarization -induced $\mathrm{Ca}^{2+}$ entry leads to the release of glutamate to the extracellular space. This release results sequentially in an activation of presynaptic mGluR2/3 receptors, (located in interneurons), inhibition of adenylate cyclase, decrease of the presynaptic cAMP concentration and decrease of GABA release. It is noteworthy that MP administration reduces GABA level and glutamate decarboxilase cerebellar activity [37]. Then the GABA levels or similar induced responses could be the link between $\mathrm{CPA}$ and MP effect on both mGluR

The effect of repetitive CPA and MP administration on the mGluR2/3 and mGluR4a immunoreativity showed an analogous behavior that our previous observations on $\left[{ }^{3} \mathrm{H}\right]$-CCPA and $\left[{ }^{3} \mathrm{H}\right]$-MK 801 binding to different brain areas, after a single injection of these compounds $[15,22]$. Similar observations were reported respect to oxygen consumption which is increased after MP administration, or after the administration of phenobarbital alone, the later having anticonvulsant properties, that avoids MP seizures [38].

About the mechanism involved on the CPA administration on mGluR 2/3 and 4a on MP-induced seizures in cerebellum, we might suggest that the effect of CPA administration on mGluR 2/3 could be associated to a protective mechanism. CPA effect administered alone or before MP, on Purkinje cells containing mGluR4a might induce either structural changes on these cells or an internalization of membrane receptors, although an apoptotic effect could be also considered.

In agreement with this it was reported that chronic treatment with CPA results in a pronounced increase in seizure intensity and seizure-associated mortality, which is an observation opposite to the protective effect observed in acute treatment [39]. Boeck et al. [40] have described that A1 receptors antagonists protect cells, but CPA alone had no effect on glutamate-induced damage, glutamate neurotoxicity, and cellular death in cerebellar granulare cells.

Although adenosine is considered to act as a neuroprotector having anticonvulsant properties, it was reported that CPA administration activate adenosine $\mathrm{A} 1 \mathrm{R}$ and induces white matter and neuronal loss in 3-to 14 postnatal day rats [41]. Moreover the activation of adenosine receptor A1R with CPA enhances neurotoxicity caused by kainate in cortical cultures neurons [42]. Besides adenosine did not promote Purkinje cell survival in rat cerebellar culture [43] and repeated treatment with the analogue 2chloro-N6-cyclopentyladenosine, a selective adenosine A1 receptor agonist, decreases the anticonvulsant properties of 3-(2 carboxypiperazine-4y) propenyl-1phosphonic acid (CPPene) against audiogenic seizures [44].

In our experiments we have observed that CPA administration during 4 days induce mGluR $2 / 3$ and $4 a$ changes in a similar way to MP administration. We have previously described an increased expression of the mdr-gene product, the P-gp protein after 4 days of MP treatment [45]. Increased P-gp indicates an augmented extrusion of unspecific drug administration and a possible effect on refractory epilepsy. This might explain in part the synergistic effect of both compounds. The effect of CPA after repetitive injection suggests that the modification of mGluR may be due to a long term exposure of these animals to the adenosine analogue, showing sedation and depressive symptoms. Although we have not studied the mdr-gene expression 
in this particular case, changes on its expression could not be disregarded.

It is important to note that the cerebellum presents a unique organization with regards the distribution of afferent information. It receives impulses via mossy and climbing fibers from several brain regions such as the spinal cord, the vestibular nucleus and the cerebral cortex. Purkinje axons are the only output from the cerebellar cortex. Certain neurochemical characteristic of the cerebellum may contribute to the sensitivity and vulnerability of this tissue to different compounds [17]. For example in a pentylenetetrazole seizure-induced model [46], cerebellum showed to be the most susceptible: a decrease in the amount of glutamate, glutamine, GABA, aspartate and taurine levels in cerebellum was described. However none of these amino acids change in cortex and subcortical regions [46]. Cerebellar GABAergic neurons showed a pronounced decrease in GABA synthesis as well as a decrease in glucose consumption [47]. Pratt et al. [48] reported that a single electroconvulsive shock seizure caused an increase in mRNA levels for some of the GABAA receptors subunits in the cerebellum without effect in cerebral cortex or hippocampus. In addition Purkinje cell reduced capability to recapture glutamate and to generate energy during anoxia makes them susceptible to ischemic death [49].

All treatments decreased mGluR4a immunoreactivity. MP administration can result either in a toxic effect on Purkinje cells or in a severe alteration in certain groups of cells that leads to a decrease in cerebellar immunostaining considering that it was reported that an unique dose of MP induce Purkinje morphological alteration, condensation, darkening and retraction of some of the neuronal perikaryon [37]. About this possible effect Snead et al. [50] reported a resistance to low dose pentylenetetrazol-induced absence seizures in mGluR4 knock out mice. This effect was mimicked by administration of the mGlur4 antagonist alpha-cyclopropyl-4-phosphono phenyl glycine (CPPG) in wild type mice [50].

We observed an intense immunostaining in the neuropil of the molecular layer that is in agreemente with Kinoshita et al. [51]. In addition we found mGluR4a expression around Purkinje cells. It was reported that the clustering of the group III metabotropic glutamate receptor in the cerebellar molecular layer, along the presynaptic membrane of parallel fiber synaptic terminals, might help to a rapid and effective activation of the mGluR4a by glutamate [52]. It is interesting to note that a decreased expression of the mGluR4 gene has been associated with neuronal apoptosis meanwhile an elevated mGluR4a expression or the activation of this receptor promotes survival [53]. Considering our experimental results an apoptotic event could not be disregarded.

It is worthwhile to mention that the existence of neuron interaction between mGluRs and adenosine receptors seems to involve protein kinase $\mathrm{C}$ that plays a wide spread role in the regulation of the three mGluRs' groups inhibiting neurotransmitter release at glutamate synapses $[54,55]$. Recently it was reported the mGluR4 is internalized and desensitized upon protein kinase $\mathrm{C}$ activation [56]. A similar situation could not be rule out in our model. According with the different expression of mGluR in MP-induce seizure it was reported that group II and III are segregated at the presynaptic terminal and there are distinct differences between the properties of the presynaptic action mediated by these two groups of receptors [57].

The present study shows that repetitive administration of MP and CPA induces an increased cerebellar mGluR2/3 and a decreased mGluR4a immunostaining, suggesting a distinct participation of both receptors that may be related to the differential cell distribution. A protective action and /or an apoptotic effect may not be discarded. CPA repetitive administration although increase seizure latency, cannot prevent seizure activity.

Acknowledgment This work was supported by grants of UBACYT M033 and M020 from Universidad de Buenos Aires, and CONICET (PIP $\mathrm{N}^{\circ}$ 02267, 5798) from the Consejo Nacional de Investigaciones Científicas y Técnicas. We are grateful to Mrs Susana Buglione for her collaboration in the bibliographic management of the manuscript.

\section{References}

1. Dingledine R, McBain CJ, McNamara JO (1990) Excitatory amino acid receptors in epilepsy. Trends Pharmacol Sci 11(8):334-338

2. Chapman AG (2000) Glutamate and epilepsy. J Nutr 130(4S Suppl):1043S-1045S

3. Nakanishi S (1994) Metabotropic glutamate receptors: synaptic transmission, modulation, and plasticity. Neuron 13(5):1031-1037

4. Knopfel T et al (1995) Pharmacological characterization of MCCG and MAP4 at the mGluR1b, mGluR2 and mGluR4a human metabotropic glutamate receptor subtypes. Neuropharmacology 34(8):1099-1102

5. Aramori I, Nakanishi S (1992) Signal transduction and pharmacological characteristics of a metabotropic glutamate receptor, mGluR1, in transfected $\mathrm{CHO}$ cells. Neuron 8(4):757-765

6. Martin LJ et al (1992) Cellular localization of a metabotropic glutamate receptor in rat brain. Neuron 9(2):259-270

7. Petralia RS et al (1996) The metabotropic glutamate receptors, mGluR2 and mGluR3, show unique postsynaptic, presynaptic and glial localizations. Neuroscience 71(4):949976 
8. Defagot MC, Villar MJ, Antonelli MC (2002) Differential localization of metabotropic glutamate receptors during postnatal development. Dev Neurosci 24(4):272-282

9. Ohishi $\mathrm{H}$ et al (1994) Immunohistochemical localization of metabotropic glutamate receptors, mGluR2 and mGluR3, in rat cerebellar cortex. Neuron 13(1):55-66

10. Shigemoto R et al (1997) Differential presynaptic localization of metabotropic glutamate receptor subtypes in the rat hippocampus. J Neurosci 17(19):7503-7522

11. Cartmell J, Schoepp DD (2000) Regulation of neurotransmitter release by metabotropic glutamate receptors. J Neurochem 75(3):889-907

12. Dunwiddie TV, Masino SA (2001) The role and regulation of adenosine in the central nervous system. Annu Rev Neurosci 24:31-55

13. Ribeiro JA, Sebastiao AM, de Mendonca A (2003) Participation of adenosine receptors in neuroprotection. Drug News Perspect 16(2):80-86

14. Giraldez L et al (1998) CNS adenosine A1 receptors are altered after the administration of convulsant 3-mercaptopropionic acid and cyclopentyladenosine: an autoradiographic study. Neurochem Res 23(2):175-181

15. Giraldez L, Girardi E (1995) 3H-MK801 and 3H-NECA binding change after the administration of cyclopentyl adenosine and the convulsant drug 3-mercaptopropionic acid. Comm. Biol 13:321-331

16. Giraldez L, Girardi E (1998) Modification of [3H]MK801 binding to rat brain NMDA receptors after the administration of a convulsant drug and an adenosine analogue: a quantitative autoradiographic study. Neurochem Res 23(10):1327-1336

17. Fonnum F, Lock EA (2004) The contributions of excitotoxicity, glutathione depletion and DNA repair in chemically induced injury to neurones: exemplified with toxic effects on cerebellar granule cells. J Neurochem 88(3):513-531

18. Saab CY, Willis WD (2003) The cerebellum: organization, functions and its role in nociception. Brain Res Brain Res Rev 42(1):85-95

19. Hansel C, Linden DJ, D'Angelo E (2001) Beyond parallel fiber LTD: the diversity of synaptic and non-synaptic plasticity in the cerebellum. Nat Neurosci 4(5):467-475

20. Zhu JN (2006) The cerebellar-hypothalamic circuits: Potential pathways underlying cerebellar involvement in somaticvisceral integration. Brain Res Brain Res Rev

21. Cooke PM, Snider RS (1995) Some cerebellar influences on electrically-induced cerebral seizures. Epilepsia 4:19-28

22. Velasco F (2005) Double-blind, randomized controlled pilot study of bilateral cerebellar stimulation for treatment of intractable motor seizures. Epilepsia 46(7):1071-1081

23. Vander T, Medvedovsky M, Herishanu Y (2004) Epilepsia partialis continua possibly caused by cerebellar lesion. Cerebellum 3(2):126-128

24. Girardi E, Perez Raffo G, Rodriguez de Lores Arnaiz G (1989) A study of 5'-nucleotidase activity in subcellular fractions of rat cerebellum after the administration of the convulsant 3-mercaptopropionic acid. Mol Chem Neuropathol 11(2):65-75

25. Boeck CR (2000) The modulation of ecto-nucleotidase activities by glutamate in cultured cerebellar granule cells. Neuroreport 11(4):709-712

26. Harvey AS (1996) Hemifacial seizures and cerebellar ganglioglioma: an epilepsy syndrome of infancy with seizures of cerebellar origin. Ann Neurol 40(1):91-98

27. Leifer D, Cole DG, Kowall NW (1991) Neuropathologic asymmetries in the brain of a patient with a unilateral status epilepticus. J Neurol Sci 103(2):127-135
28. Neki A (1996) Metabotropic glutamate receptors mGluR2 and mGluR5 are expressed in two non-overlapping populations of Golgi cells in the rat cerebellum. Neuroscience 75(3):815-826

29. Thomsen C et al (1994) (S)-4-carboxy-3-hydroxyphenylglycine, an antagonist of metabotropic glutamate receptor (mGluR) 1a and an agonist of mGluR2, protects against audiogenic seizures in DBA/2 mice. J Neurochem 62(6): 2492-2495

30. Folbergrova $\mathbf{J}$ et al (2005) Seizures induced in immature rats by homocysteic acid and the associated brain damage are prevented by group II metabotropic glutamate receptor agonist (2R,4R)-4-aminopyrrolidine-2,4-dicarboxylate. Exp Neurol 192(2):420-436

31. Folbergrova J, Haugvicova R, Mares P (2001) Attenuation of seizures induced by homocysteic acid in immature rats by metabotropic glutamate group II and group III receptor agonists. Brain Res 908(2):120-129

32. Tang FR et al (2004) Metabotropic glutamate receptor $2 / 3$ in the hippocampus of patients with mesial temporal lobe epilepsy, and of rats and mice after pilocarpine-induced status epilepticus. Epilepsy Res 59(2-3):167-180

33. Klodzinska A, Chojnacka-Wojcik E, Pilc A (1999) Selective group II glutamate metabotropic receptor agonist LY354740 attenuates pentetrazole- and picrotoxin-induced seizures. Pol J Pharmacol 51(6):543-545

34. Suzuki T et al (1999) Role of metabotropic glutamate receptors in the hypersusceptibility to pentylenetetrazoleinduced seizure during diazepam withdrawal. Eur J Pharmacol 369(2):163-168

35. Tizzano JP, Griffey KI, Schoepp DD (1995) Induction or protection of limbic seizures in mice by mGluR subtype selective agonists. Neuropharmacology 34(8):1063-1067

36. Glitsch M, Llano I, Marty A (1996) Glutamate as a candidate retrograde messenger at interneurone-Purkinje cell synapses of rat cerebellum. J Physiol 497(Pt 2):531-537

37. Rodriguez de Lores Arnaiz G, Alberici de Canal M, De Robertis E (1972) Alteration of GABA system and Purkinje cells in rat cerebellum by the convulsant 3-mercaptopropionic acid. J Neurochem 19(5):1379-1385

38. Rodriguez de Lores Arnaiz G, Imerito M (1980) Respiratory capacity of rat cerebral cortex mitochondria. Stimulation by convulsant and subconvulsant doses of 3-mercaptopropionic acid; contrasting effect of phenobarbitone. Acta Physiol Lat Am 30(3):221-224

39. Jacobson KA et al (1996) Adenosine receptor ligands: differences with acute versus chronic treatment. Trends Pharmacol Sci 17(3):108-113

40. Boeck CR et al (2005) Adenosine receptors co-operate with NMDA preconditioning to protect cerebellar granule cells against glutamate neurotoxicity. Neuropharmacology 49(1): $17-24$

41. Turner CP et al (2002) A1 adenosine receptor activation induces ventriculomegaly and white matter loss. Neuroreport 13(9):1199-1204

42. Rebola $\mathrm{N}$ et al (2005) Different roles of adenosine A1, A2A and $\mathrm{A} 3$ receptors in controlling kainate-induced toxicity in cortical cultured neurons. Neurochem Int 47(5):317-325

43. Watanabe S, Yoshimi Y, Ikekita M (2003) Neuroprotective effect of adenine on purkinje cell survival in rat cerebellar primary cultures. J Neurosci Res 74(5):754-759

44. De Sarro G et al (1996) Repeated treatment with adenosine A1 receptor agonist and antagonist modifies the anticonvulsant properties of CPPene. Eur J Pharmacol 317(2-3): 239-245 
45. Lazarowski A et al (2004) Neuronal and glial expression of the multidrug resistance gene product in an experimental epilepsy model. Cell Mol Neurobiol 24(1):77-85

46. Eloqayli $\mathrm{H}$ et al (2003) Pentylenetetrazole decreases metabolic glutamate turnover in rat brain. $J$ Neurochem 85(5):1200-1207

47. Walsh LA et al (1999) Acute pentylenetetrazol injection reduces rat GABAA receptor mRNA levels and GABA stimulation of benzodiazepine binding with No effect on benzodiazepine binding site density. J Pharmacol Exp Ther 289(3):1626-1633

48. Pratt JS et al (1993) Electroconvulsive shock alters GABAA receptor subunit mRNAs: use of quantitative PCR methodology. Brain Res Bull 30(5-6):691-693

49. Welsh JP et al (2002) Why do Purkinje cells die so easily after global brain ischemia? Aldolase C, EAAT4, and the cerebellar contribution to posthypoxic myoclonus. Adv Neurol 89:331-359

50. Snead OC III et al (2000) Modulation of absence seizures by the $\operatorname{GABA}(\mathrm{A})$ receptor: a critical rolefor metabotropic glutamate receptor 4 (mGluR4). J Neurosci 20(16):6218-6224

51. Kinoshita A et al (1996) Presynaptic localization of a metabotropic glutamate receptor, mGluR4a, in the cerebel- lar cortex: a light and electron microscope study in the rat. Neurosci Lett 207(3):199-202

52. Mateos JM et al (1999) Clustering of the group III metabotropic glutamate receptor $4 \mathrm{a}$ at parallel fiber synaptic terminals in the rat cerebellar molecular layer. Neurosci Res 35(1):71-74

53. Borodezt K, D'Mello SR (1998) Decreased expression of the metabotropic glutamate receptor-4 gene is associated with neuronal apoptosis. J Neurosci Res 53(5):531-541

54. Sebastiao AM, Ribeiro JA (2000) Fine-tuning neuromodulation by adenosine. Trends Pharmacol Sci 21(9):341-346

55. Alagarsamy S, Sorensen SD, Conn PJ (2001) Coordinate regulation of metabotropic glutamate receptors. Curr Opin Neurobiol, 2001. 11(3):357-362

56. Mathiesen JM, Ramirez MT (2006) The metabotropic glutamate receptor 4 is internalized and desensitized upon protein kinase C activation. Br J Pharmacol 148(3):279-290

57. Capogna M (2004) Distinct properties of presynaptic group II and III metabotropic glutamate receptor-mediated inhibition of perforant pathway-CA1 EPSCs. Eur J Neurosci 19(10):2847-2858 